\title{
Tissue-Engineered Larynx: Future Applications in Laryngeal Cancer
}

\author{
Nick J. I. Hamilton ${ }^{1} \cdot$ Martin A. Birchall ${ }^{1}$ \\ Published online: 14 March 2017 \\ (C) The Author(s) 2017. This article is published with open access at Springerlink.com
}

\begin{abstract}
Purpose of Review This article reviews the latest developments in tissue engineering for the larynx with a specific focus on the treatment of laryngeal cancer.

Recent Findings Challenges in tissue engineering a total larynx can be divided into scaffold design, methods of remucosalization, and how to restore laryngeal function. The literature described a range of methods to deliver a laryngeal scaffold including examples of synthetic, biomimetic, and biological scaffolds. Methods to regenerate laryngeal mucosa can be divided into examples that use a biological dressing and those that engineer a new mucosal layer de novo. Studies aiming to restore laryngeal function have been reported, but to date, the optimum method for achieving this as part of a total laryngeal transplant is yet to be determined.

Summary There is great potential for tissue engineering to improve the treatments available for laryngeal cancer within the next 10 years. A number of challenges exist however and advances in restoring function must keep pace with developments in scaffold design.
\end{abstract}

Keywords Tissue engineering $\cdot$ Larynx $\cdot$ Regenerative medicine $\cdot$ Laryngeal cancer $\cdot$ Larynx transplant

This article is part of the Topical Collection on Head and Neck: Laryngeal Cancer

Nick J. I. Hamilton

nick.hamilton@ucl.ac.uk

1 University College London Ear Institute, Gray’s Inn Road, London, UK

\section{Introduction}

Laryngeal cancer is the second most common airway cancer after lung cancer with an estimated global incidence of 157,000 per annum [1]. Within the USA, an estimated 13,430 new cases have been diagnosed in 2016 with an estimated annual mortality of 3620 [2]. Conventional treatments for advanced laryngeal cancer can be divided into surgical and organ preserving treatments. Surgical therapies involve either a total or partial laryngectomies. Total laryngectomy involves the complete resection of the larynx with the creation of a tracheostome to create a new airway and a neo-pharynx to preserve swallowing. Whilst this offers the chance for wide surgical margins and good swallow function [3, 4], voice rehabilitation is variable and there are additional psychological and social impacts of having a permanent tracheostome that impact on the quality of life $[5,6]$. Partial laryngectomy encompasses procedures involving a sub-total resection of the larynx to preserve function whilst aiming to achieve similar rates of cure as total laryngectomy [7]. Function and quality of life assessments have been demonstrated to be higher with this approach compared to total laryngectomy although the subset of patients in which this resection is possible is small and problems with aspiration remain [8-10]. Organ preserving therapies involve chemo-radiation with curative intent whilst leaving the anatomical structures of the larynx to preserve function. Survival rates have been shown to be comparable to surgical treatments although swallow dysfunction and other complications such as dryness and mucositis mean the optimal form of treatment remains a source of on-going debate [11-13]. The limitations of these treatment modalities have led some to explore whether tissue engineering could provide new therapeutic options.

Tissue engineering applies the principles of biological and material science with engineering to restore or replace 
damaged tissue or organs. The ability to transplant a functioning tissue-engineered larynx would revolutionize the treatment of laryngeal cancer by providing comparable rates of cure to conventional treatments whilst preserving function. Total cadaveric laryngeal transplantation has been reported twice in the literature and demonstrates the feasibility of total laryngeal replacement $[14,15]$. A 14-year follow-up of the first transplant describes how after a 10-year period, a slow progressive chronic rejection process led to the organ becoming nonfunctional and the larynx being explanted [16]. It is possible that a tissue-engineered larynx would avoid this as it would be repopulated with the patient's own cells. To date, reports on the delivery of a complete and functioning tissueengineered larynx are however absent from the literature. The challenges involved in realizing this ambition are multiple and can be divided into challenges in scaffold design, re-epithelialization, and restoring laryngeal function.

\section{Scaffold Design of a Tissue-Engineered Larynx}

A tissue-engineered total laryngeal replacement would require a scaffold that integrates with the host tissue, provides adequate structural support, and allows for mobility to enable laryngeal function. The first obvious target would be to engineer the larynx from the regenerated cartilage. Cartilage has the advantage of being biocompatible and exhibits a high tensile strength whilst retaining elasticity. The ability to engineer the cartilage in vitro has been extensively reported using a variety of protocols [17-20]. In brief, the cartilage is harvested from an autologous source such as the septum or auricle; the chondrocytes separated and expanded in vitro before reseeding onto a scaffold made from either biological, synthetic or biomimetic material. The successful integration in vivo of the engineered cartilage has remained problematic, however, with reports documenting strong inflammatory responses and rapid degradation as well as difficulties in restoring an adequate blood supply following transplantation [17, 21]. To overcome this, the principle of in vivo tissue engineering has been applied whereby the cartilage regenerates within a vascularized structure in vivo to enable transplantation with a preserved blood supply. An example of this can be seen in work by Kamil et al. where chondrocytes sourced from auricular cartilage were suspended in a biodegradable polymer and implanted in the dorsum of a pig [22]. After 2 months, a complete cartilage graft was harvested and used as part of a laryngotracheal reconstruction with bronchoscopy and histology demonstrating complete integration of the graft into the host tissue.

The use of synthetic or biomimetic scaffolds has the advantage over cartilage scaffolds in that they can be more easily fabricated to a specific size and shape and within a shorter period of time. Several studies have reported on the use of a polyprolene mesh coated with a spongy porcine collagen manufactured using a dental cast of a hemilarynx [23, 24]. Following hemilaryngectomy in a canine model, the construct is transplanted with a pre-clotted mixture of peripheral blood and bone marrow-derived stromal cells or a fascia lata wrap. After the first week, evidence of neo-mucosalization is demonstrated and the constructs had integrated within the host tissue.

Titanium has been used to reconstruct laryngotracheal resections for airway stenosis in a number of cases with the additional use of silk fibroin to facilitate better mucosal healing [25-28]. Titanium is an attractive synthetic material as it is hypoallergenic and comparatively cheap and has an extensive safety profile in other applications such as laryngeal fixation following fracture [29, 30]. Liu et al. used a titanium mesh to reconstruct laryngeal defects in nine patients following frontolateral vertical partial laryngectomy for T2 or T3 glottic cancer with the sternohyoid muscle being used to cover the mucosal surface of the mesh and the outer surface covered by omohyoid muscle [31]. No aspiration or laryngeal stenosis was observed following implantation and fiberoptic inspection showed the mesh remained covered in the long term.

Biological scaffolds can be fabricated by decellularizing donor tissue to remove the cellular content and thus immune potential whilst retaining the extracellular matrix proteomic cues that act as a map for regenerating cells [32]. Ansari et al. used a $6 \times 4 \times 2 \mathrm{~m}$ section of decellularized porcine larynx to replace a rectangular laryngeal defect in a pig model [33]. The scaffold was pre-implanted within a neck muscle flap for 4 weeks to re-vascularize before a sheet of engineered buccal mucosa was grafted onto the surface and the construct rotated on a muscle flap to repair the defect. Serial endoscopy and computer tomography imaging showed the graft integrated within this host tissue and a layer of neo-mucosa regenerated within the first month. None of the six grafts implanted led to any compromise in respiratory or swallowing function.

Aortic homografts are widely documented as a means of reconstructing tracheal defects and are available as "off the shelf" products that can be rapidly sourced and easily stored [34-38]. They also retain the extracellular matrix needed for successful regeneration and exhibit little immune response from the recipient [38-40]. Zeitels et al. used cryopreserved aortic homografts to reconstruct laryngeal defects in 15 patients undergoing partial laryngectomy for cancer [41]. The strap or sternocleidomastoid muscles were affixed to the extraluminal surface to promote revascularization, and a tracheostomy was sited in all patients to protect the graft in the initial post-operative phase. All of the 15 patients were successfully decannulated by 10 weeks and exhibited laryngeal phonation. Complete epithelialization took between 3 and 5 months and all but one of the patients resumed oral intake. Whilst this study demonstrates the success in using biological tissue to reconstruct partial defects, the subset of patients for 
which this type of resection is indicated is small and comparative studies with conventional reconstructive methods following partial laryngectomy are yet to be performed.

\section{Tissue Engineering to Restore Mucosal Function}

Following scaffold selection, the means by which the mucosal layer will be restored needs to be determined. An intact mucosal layer is essential in any transplantation as it provides a barrier against infection. In laryngeal transplantation, this is even more relevant as the implant will be exposed to airborne pathogens during respiration. Mucosa also has a number of organ-specific specialized functions. Within the larynx, the lamina propria layer of the vocal folds needs to be sufficiently viscoelastic to allow for the transmission of the vibratory wave during phonation. Conventional methods of tissue replacement are not appropriate for restoring the mucosal layer in an engineered laryngeal transplant. Split skin grafts are associated with keratinization that leads to sloughing and infection within the airway, and buccal mucosal grafts are restricted by a limited supply of donor tissue. Myocutaneous flaps are ideal for reconstructing large defects but are too bulky to reline the complex three-dimensional surface of the larynx.

To achieve re-mucosalization of the laryngeal scaffold, several options are available.

The first is to rely on the migration of the host's native epithelial cells to regenerate a new mucosal layer following implantation, a process that can be potentiated by the use of decellularized or biomimetic scaffolds that provide a favorable matrix environment for regenerating epithelium [42]. The delay in achieving re-mucosalization places that scaffold material at risk of infection, although this risk can be negated by the use of biological dressings, as seen with the use of a fascia lata flap and clotted peripheral blood in works by Yamashita and Kitani et al. [23, 24]. An alternative method might be to embed the mucosal surface of the scaffold with pro-migratory factors such as Rho-kinase inhibitor to potentiate the reepithelialization process [43, 44].

Another option to achieve re-mucosalization is to tissue engineer a separate mucosal layer and graft it onto the scaffold either before or during implantation. There are a number of examples demonstrating how stratified squamous mucosa can be engineered using autologous squamous cells expanded from a small biopsy and seeded onto decellularized dermis or collagen scaffolds (Fig. 1) [45, 46]. As with the engineered cartilage, difficulties arise in grafting the in vitro engineered mucosa onto a scaffold as, for the mucosa to survive, the scaffold requires a blood supply to deliver nutrition to the epithelial layer. Pre-vascularizing the scaffold within a muscle flap is a potential solution and allowed for the successful grafting of buccal mucosal grafts onto cadaveric trachea embedded within radial forearm fascia in a series of partial a

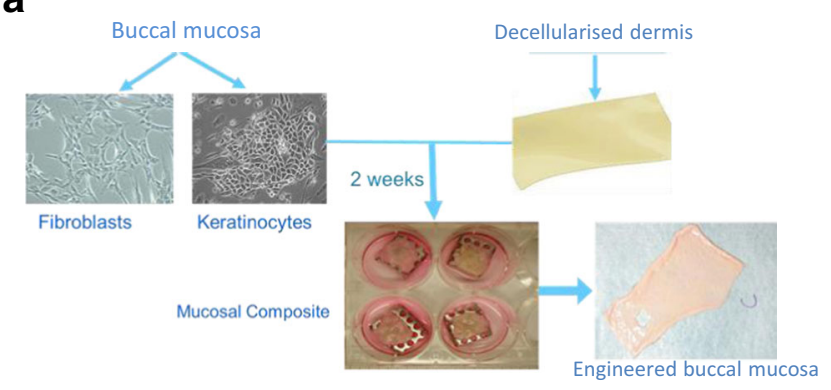

b

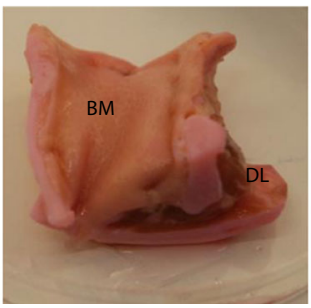

Fig. 1 Tissue engineering buccal mucosa. a A biopsy of buccal mucosa is taken and the epithelial cells and fibroblasts separated. These cells are then expanded in culture and seeded onto a sheet of decellularized human dermis. The construct is then matured at air-liquid interface to promote differentiation. b A section of tissue-engineered buccal mucosa $(B M)$ is sutured onto a decellularized hemilarynx $(D L)$ in vitro to restore the mucosal layer in vitro

human tracheal transplants [47]. A similar method was employed in the study by Ansari et al. where a segment of decellularized porcine larynx was embedded within a neck muscle flap and engineered squamous mucosa grafted onto the surface 4 weeks later once a new blood supply had been restored [33]. In this instance, the mucosa did not appear to survive and acted as a biological dressing, protecting the scaffold, whilst the host's native epithelial cells covered the defect. It could be argued that current examples of tissue-engineered mucosa are not suitable for relining complex threedimensional scaffolds as the epithelial layer is exposed to shear during the implantation phase and there is a delay in re-vascularizing the epithelium following grafting leading to cell death. A potential solution could be to implant epithelial cells encased within collagen gel containing growth factors and/or mesenchymal cells that provide support to the epithelium whilst a blood supply is re-established. A similar technique has been used in gut engineering to reline a section of decellularized small intestine [48].

Studies aiming to restore the viscoelastic properties of the vocal fold lamina propria mainly involve the use of injectable gels such as synthetic hyaluronic acid-dextran [49], hyaluronic acid-based microgels [50], and collagen I composites [51]. These materials exhibit similar viscoelastic properties to healthy vocal fold lamina propria and are believed to be pro-regenerative leading to a restoration of a viscoelastic layer overtime [52]. The optimum material is still undecided however and whether a completely new lamina propria layer could be restored in an engineered vocal fold is yet to be determined 
as the majority of the studies examine the role of injectables in vocal fold scarring $[53,54]$.

\section{Tissue Engineering to Restore Dynamic Function}

The larynx is a dynamic organ. During inspiration, the vocal folds abduct to allow airflow and during phonation, the folds adduct to generate vibration. During swallowing, there are a complex series of movements involving closure of the vocal and false cords, elevation of the larynx, and reflection of the epiglottis to prevent aspiration. A tissue-engineered total laryngeal transplant would need to be able to provide all of these functions if it is to overcome the shortcomings of conventional treatments. A partial laryngeal transplant might not require full function providing the cricoarytenoid-nervemuscle unit is preserved in the un-resected larynx. The tissue-engineered partial implant would aim to improve upon the functional outcome of existing reconstructive techniques following partial laryngectomy, namely problems with aspiration.

The cricoarytenoid-nerve-muscle unit needs to be reestablished in order to restore vocal fold movement. This would require the laryngeal scaffold to have a functioning cricoarytenoid joint, the successful regeneration and grafting of the cricoarytenoid muscles, and regeneration of the muscle's nerve supply with appropriate central control. The success of conventional joint replacement limits the role of tissue engineering within this field to articular cartilage regeneration to treat damage to existing joints $[55,56]$. Advances in nanoengineering might in the future deliver workable and biocompatible joint replacements small enough to restore cricoarytenoid movement but so far, examples of the application of this technology for this purpose are absent from the literature.

The use of tissue engineering techniques to regenerate the organized skeletal muscle has been well documented [57-59], although studies regenerating the cricoarytenoid muscle specifically are lacking. Fishman et al. demonstrated that rabbit cricoarytenoid dorsalis treated with latrunculin B, potassium iodide, potassium chloride, and deoxyribonuclease achieves total clearance of host DNA with preservation of the scaffold structural integrity and matrix components [60]. This provides a decellularized cricoarytenoid muscle that can act as a scaffold to regenerate a functioning cricoarytenoid muscle.

Reinnervation of the adductor and abductor cricoarytenoid muscles is currently performed to prevent vocal cord muscle atrophy and promote movement during respiration in cases of vocal fold paralysis. The procedure is performed by means of direct anastomosis of the adductor branch of recurrent laryngeal nerve with the ansa cervicalis and anastomosis of the abductor branch to the phrenic nerve [61-63]. Reports on functional outcome following reinnervation are promising [63-65] and demonstrate the feasibility of this technique to restore motor function in a tissue-engineered laryngeal transplant. The engineered cricoarytenoid muscle would either have to include neuromuscular endplates and a regenerated laryngeal nerve to anastomose onto the existing laryngeal nerve supply or the native laryngeal nerve would need to be anastomosed directly onto the regenerated cricoarytenoid muscle.

An alternative to reinnervation is the use of laryngeal pacing. Pacing involves the insertion of electrodes into the posterior cricoarytenoid muscle which deliver a time-phased electric signal that is in sync with the respiratory cycle to stimulate abduction of the vocal folds during inspiration [66]. This technology has been trailed in seven human patients with two of the seven subjects exhibiting full reanimation for greater than 4 years [67]. Problems with biocompatibility and the lack of a sensor to pace abduction with inspiration have meant this technology has not been widely adopted.

The restoration of swallowing function is more complex because of the need for a coordinated series of laryngeal movements. Transcutaneous neuromuscular electrical stimulation of the pharyngeal muscles has been used to bring about a coordinated muscle contraction in stroke patients suffering with dysphagia with promising results [68], and this technique could be adapted to reinnervate the larynx and coordinate the swallowing mechanism. Soft robotics aims to deliver robotic devices that are flexible and can potentially be used as implants. This could deliver fully automated laryngeal movement to restore swallow and voice although the technology is still in the early development phases $[69,70]$. A more rudimentary example of a mechanical larynx has been trialed using a titanium prosthesis with a concentric valve system that opens to allow respiration and closes to avoid aspiration during swallowing. Pre-clinical studies were encouraging in terms of prosthetic integration [71, 72], although in the single human case reported, the patient was still tracheostomy dependent and due to the absence of a glottic sphincter phonation was poor [73]. Long-term follow-up of this case and a clinical trial involving this technology has not yet been published.

\section{Conclusions}

There is great potential for tissue engineering to revolutionize the treatment of laryngeal cancer in the form of a partial or total laryngeal transplant within the next 10 years. A number of challenges remain which are best addressed by a coordinated effort involving biological and material scientists, engineers, surgeons, and allied health professionals. A decision on the choice of scaffold and the optimal method of achieving 
integration with revascularization should form any early milestone and should be developed in continuity with methods of achieving complete re-mucosalization. Without function, total laryngeal replacement would not be able to greatly improve upon existing treatments for laryngeal cancer. Developments in restoring laryngeal function must therefore keep pace with developments in laryngeal scaffold and mucosal engineering.

\section{Compliance with Ethical Standards}

Conflict of Interest The authors declare that they have no conflicts of interest.

Human and Animal Rights and Informed Consent This article does not contain any studies with human or animal subjects performed by any of the authors.

Open Access This article is distributed under the terms of the Creative Commons Attribution 4.0 International License (http:// creativecommons.org/licenses/by/4.0/), which permits unrestricted use, distribution, and reproduction in any medium, provided you give appropriate credit to the original author(s) and the source, provide a link to the Creative Commons license, and indicate if changes were made.

\section{References}

Papers of particular interest, published recently, have been highlighted as:

- Of importance

• Of major importance

1. Cattaruzza MS, Maisonneuve P, Boyle P. Epidemiology of laryngeal cancer. Eur J Cancer B Oral Oncol. 1996;32B(5):293-305.

2. SEER Stat Fact Sheets: Larynx Cancer USA: National Cancer Institute 2016 [Available from: http://seer.cancer.gov/statfacts/ html/laryn.html.

3. Bajaj Y, Shayah A, Sethi N, Harris AT, Bhatti I, Awobem A, et al. Clinical outcomes of total laryngectomy for laryngeal carcinoma. Kathmandu Univ Med J (KUMJ). 2009;7(27):258-62.

4. Basheeth N, O'Leary G, Khan H, Sheahan P. Oncologic outcomes of total laryngectomy: impact of margins and preoperative tracheostomy. Head Neck. 2015;37(6):862-9.

5. Pereira da Silva A, Feliciano T, Vaz Freitas S, Esteves S, Almeida ESC. Quality of life in patients submitted to total laryngectomy. J Voice. 2015;29(3):382-8.

6. Agarwal SK, Gogia S, Agarwal A, Agarwal R, Mathur AS. Assessment of voice related quality of life and its correlation with socioeconomic status after total laryngectomy. Ann Palliat Med. 2015;4(4):169-75.

7. Pinar E, Imre A, Calli C, Oncel S, Katilmis H. Supracricoid partial laryngectomy: analyses of oncologic and functional outcomes. Otolaryngol Head Neck Surg. 2012;147(6):1093-8.

8. Benito J, Holsinger FC, Perez-Martin A, Garcia D, Weinstein GS, Laccourreye O. Aspiration after supracricoid partial laryngectomy: incidence, risk factors, management, and outcomes. Head Neck. 2011;33(5):679-85.

9. Sanchez-Cuadrado I, Castro A, Bernaldez R, Del Palacio A, Gavilan J. Oncologic outcomes after supracricoid partial laryngectomy. Otolaryngol Head Neck Surg. 2011;144(6):910-4.
10. Shenoy AM, Sridharan S, Srihariprasad AV, Reddy BK, Anand VT, Premalatha BS, et al. Near-total laryngectomy in advanced cancers of the larynx and pyriform sinus: a comparative study of morbidity and functional and oncological outcomes. The Annals of otology, rhinology, and laryngology. 2002;111:50-6.

11. Grover S, Swisher-McClure S, Mitra N, Li J, Cohen RB, Ahn PH, et al. Total laryngectomy versus larynx preservation for T4a larynx cancer: patterns of care and survival outcomes. Int J Radiat Oncol Biol Phys. 2015;92(3):594-601.

12. Haddad R. Larynx preservation: a debate worth preserving. J Clin Oncol. 2013;31(25):3170.

13. Wolf GT. Options for preserving the larynx in patients with advanced laryngeal and hypopharyngeal cancer. Ear Nose Throat J. 2001;80(12):897-901.

14. Strome M, Stein J, Esclamado R, Hicks D, Lorenz RR, Braun W, et al. Laryngeal transplantation and 40-month follow-up. N Engl J Med. 2001;344(22):1676-9.

15.•• Farwell DG, Birchall MA, Macchiarini P, Luu QC, de Mattos AM, Gallay BJ, et al. Laryngotracheal transplantation: technical modifications and functional outcomes. Laryngoscope. 2013;123(10): 2502-8. A key paper demonstrating the feasibility of a total laryngeal transplant

16. Lorenz RR, Strome M. Total laryngeal transplant explanted: 14 years of lessons learned. Otolaryngol Head Neck Surg. 2014;150(4):509-11.

17. Rotter N, Haisch A, Bucheler M. Cartilage and bone tissue engineering for reconstructive head and neck surgery. Eur Arch Otorhinolaryngol. 2005;262(7):539-45.

18. Wambach BA, Cheung H, Josephson GD. Cartilage tissue engineering using thyroid chondrocytes on a type I collagen matrix. Laryngoscope. 2000;110(12):2008-11.

19. Vinatier C, Guicheux J. Cartilage tissue engineering: from biomaterials and stem cells to osteoarthritis treatments. Ann Phys Rehabil Med. 2016;59(3):139-44.

20. Visscher DO, Bos EJ, Peeters M, Kuzmin NV, Groot ML, Helder $\mathrm{MN}$, et al. Cartilage tissue engineering: preventing tissue scaffold contraction using a 3D-printed polymeric cage. Tissue Eng Part C Methods. 2016;22(6):573-84.

21. Gugatschka M, Ohno S, Saxena A, Hirano S. Regenerative medicine of the larynx. Where are we today? A review. J Voice. 2012;26(5):670. e7-13

22. Kamil SH, Eavey RD, Vacanti MP, Vacanti CA, Hartnick CJ. Tissue-engineered cartilage as a graft source for laryngotracheal reconstruction: a pig model. Arch Otolaryngology Head Neck Surg. 2004;130(9):1048-51.

23. Kitani Y, Kanemaru S, Umeda H, Suehiro A, Kishimoto Y, Hirano $\mathrm{S}$, et al. Laryngeal regeneration using tissue engineering techniques in a canine model. Ann Otol Rhinol Laryngol. 2011;120(1):49-56.

24. Yamashita M, Omori K, Kanemaru S, Magrufov A, Tamura Y, Umeda H, et al. Experimental regeneration of canine larynx: a trial with tissue engineering techniques. Acta Otolaryngol Suppl. 2007;557:66-72.

25. Daneshi A, Mohammadi S, Hassannia F. Delayed laryngotracheal reconstruction with titanium plate: report of 10 cases. J Voice. 2010;24(6):755-7.

26. Gaafar AA, El-Daly AA, Gaafar HA. Laryngotracheal augmentation using titanium mesh. J Laryngol Otol. 2008;122(4):391-6.

27. Janssen LM, van Osch GJ, Li JP, Kops N, de Groot K, Feenstra L, et al. Laryngotracheal reconstruction with porous titanium in rabbits: are vascular carriers and mucosal grafts really necessary? J Tissue Eng Regen Med. 2010;4(5):395-403.

28. Ni YS, Zhao X, Zhou L, Yan WH, Shao ZZ, Chen X, et al. Role of titanium mesh coated with silk fibroin in rabbit tracheal reconstruction. Zhonghua Er Bi Yan Hou Tou Jing Wai Ke Za Zhi. 2005;40(12):887-92. 
29. de Mello-Filho FV, Carrau RL. The management of laryngeal fractures using internal fixation. Laryngoscope. 2000;110(12):2143-6.

30. Jalisi S, Zoccoli M. Management of laryngeal fractures - a 10-year experience. J Voice. 2011;25(4):473-9.

31. Liu XK, Zhang Q, Li Q, Liu WW, Li H, Zeng ZY, et al. Laryngeal framework reconstruction using titanium mesh in glottic cancer after frontolateral vertical partial laryngectomy. Laryngoscope. 2010;120(11):2197-202.

32. Frantz C, Stewart KM, Weaver VM. The extracellular matrix at a glance. J Cell Sci. 2010;123(Pt 24):4195-200.

33. Ansari T, Lange P, Southgate A, Greco K, Carvalho C, Partington $\mathrm{L}$, et al. Stem cell-based tissue-engineered laryngeal replacement. Stem cells translational medicine. 2016.

34. Makris D, Holder-Espinasse M, Wurtz A, Seguin A, Hubert T, Jaillard S, et al. Tracheal replacement with cryopreserved allogenic aorta. Chest. 2010;137(1):60-7.

35. Marquette $\mathrm{CH}$, Wurtz A. Tracheal replacement with aortic allografts in the pig. Ann Thorac Surg. 2010;90(6):2091. author reply -2 .

36. Martinod E, Seguin A, Holder-Espinasse M, Kambouchner M, Duterque-Coquillaud M, Azorin JF, et al. Tracheal regeneration following tracheal replacement with an allogenic aorta. Ann Thorac Surg. 2005;79(3):942-8. discussion 9

37. Martinod E, Seguin A, Pfeuty K, Fornes P, Kambouchner M, Azorin JF, et al. Long-term evaluation of the replacement of the trachea with an autologous aortic graft. Ann Thorac Surg. 2003;75(5):1572-8. discussion 8

38. Wurtz A, Porte H, Conti M, Desbordes J, Copin MC, Azorin J, et al. Tracheal replacement with aortic allografts. N Engl J Med. 2006;355(18):1938-40.

39. Seguin A, Radu D, Holder-Espinasse M, Bruneval P, FialaireLegendre A, Duterque-Coquillaud M, et al. Tracheal replacement with cryopreserved, decellularized, or glutaraldehyde-treated aortic allografts. Ann Thorac Surg. 2009;87(3):861-7.

40. Wurtz A, Hysi I. Tracheal replacement with aortic allografts in humans. Experimental prospects. Rev Mal Respir. 2012;29(7): 941-4.

41. Zeitels SM, Wain JC, Barbu AM, Bryson PC, Burns JA. Aortic homograft reconstruction of partial laryngectomy defects: a new technique. Ann Otol Rhinol Laryngol. 2012;121(5):301-6.

42. Badylak SF, Gilbert TW. Immune response to biologic scaffold materials. Semin Immunol. 2008;20(2):109-16.

43. Miyashita H, Yokoo S, Yoshida S, Kawakita T, Yamagami S, Tsubota K, et al. Long-term maintenance of limbal epithelial progenitor cells using rho kinase inhibitor and keratinocyte growth factor. Stem Cells Transl Med. 2013;2(10):758-65.

44. Suprynowicz FA, Upadhyay G, Krawczyk E, Kramer SC, Hebert JD, Liu X, et al. Conditionally reprogrammed cells represent a stem-like state of adult epithelial cells. Proc Natl Acad Sci U S A. 2012;109(49):20035-40.

45. Bhargava S, Chapple CR, Bullock AJ, Layton C, MacNeil S. Tissue-engineered buccal mucosa for substitution urethroplasty. BJU Int. 2004;93(6):807-11.

46. Braziulis E, Diezi M, Biedermann T, Pontiggia L, Schmucki M, Hartmann-Fritsch F, et al. Modified plastic compression of collagen hydrogels provides an ideal matrix for clinically applicable skin substitutes. Tissue Eng Part C Methods. 2012;18(6):464-74.

47. Delaere PR. Tracheal transplantation. Curr Opin Pulm Med. 2012;18(4):313-20.

48. Shaffiey SA, Jia H, Keane T, Costello C, Wasserman D, Quidgley $\mathrm{M}$, et al. Intestinal stem cell growth and differentiation on a tubular scaffold with evaluation in small and large animals. Regen Med. 2016;11(1):45-61. Highlights the potential for autologous stem cells to be implanted in-vivo to regenerate an epithelial lining

49. Luo Y, Kobler JB, Heaton JT, Jia X, Zeitels SM, Langer R. Injectable hyaluronic acid-dextran hydrogels and effects of implantation in ferret vocal fold. J Biomed Mater Res B Appl Biomater. 2010;93(2):386-93.

50. Jia X, Yeo Y, Clifton RJ, Jiao T, Kohane DS, Kobler JB, et al. Hyaluronic acid-based microgels and microgel networks for vocal fold regeneration. Biomacromolecules. 2006;7(12):3336-44.

51. Hahn MS, Teply BA, Stevens MM, Zeitels SM, Langer R. Collagen composite hydrogels for vocal fold lamina propria restoration. Biomaterials. 2006;27(7):1104-9.

52. Thibeault SL, Klemuk SA, Chen X, Quinchia Johnson BH. In vivo engineering of the vocal fold ECM with injectable HA hydrogelslate effects on tissue repair and biomechanics in a rabbit model. $\mathrm{J}$ Voice. 2011;25(2):249-53.

53. Hirano S, Bless DM, Rousseau B, Welham N, Montequin D, Chan RW, et al. Prevention of vocal fold scarring by topical injection of hepatocyte growth factor in a rabbit model. Laryngoscope. 2004;114(3):548-56.

54. Fishman JM, Long J, Gugatschka M, De Coppi P, Hirano S, Hertegard S, et al. Stem cell approaches for vocal fold regeneration. Laryngoscope. 2016;126(8):1865-70.

55. Johnstone B, Alini M, Cucchiarini M, Dodge GR, Eglin D, Guilak $\mathrm{F}$, et al. Tissue engineering for articular cartilage repair - the state of the art. Eur Cells Mater. 2013;25:248-67.

56. Liu M, Yu X, Huang F, Cen S, Zhong G, Xiang Z. Tissue engineering stratified scaffolds for articular cartilage and subchondral bone defects repair. Orthopedics. 2013;36(11):868-73.

57. Das M, Rumsey JW, Bhargava N, Stancescu M, Hickman JJ. Skeletal muscle tissue engineering: a maturation model promoting long-term survival of myotubes, structural development of the excitation-contraction coupling apparatus and neonatal myosin heavy chain expression. Biomaterials. 2009;30(29):5392-402.

58. Qazi TH, Mooney DJ, Pumberger M, Geissler S, Duda GN. Biomaterials based strategies for skeletal muscle tissue engineering: existing technologies and future trends. Biomaterials. 2015;53: 502-21. Excellent overview on the subject of skeletal tissueengineering

59.• Fuoco C, Petrilli LL, Cannata S, Gargioli C. Matrix scaffolding for stem cell guidance toward skeletal muscle tissue engineering. J Orthop Surg Res. 2016;11(1):86. This paper highlights the importance of considering the extracellular matrix in achieving successful tissue regeneration

60. Fishman JM, Ansari T, Sibbons P, De Coppi P, Birchall MA. Decellularized rabbit cricoarytenoid dorsalis muscle for laryngeal regeneration. Ann Otol Rhinol Laryngol. 2012;121(2):129-38.

61. DeConde AS, Long JL, Armin BB, Berke GS. Functional reinnervation of vocal folds after selective laryngeal adductor denervationreinnervation surgery for spasmodic dysphonia. J Voice. 2012;26(5):602-3.

62. Marina MB, Marie JP, Birchall MA. Laryngeal reinnervation for bilateral vocal fold paralysis. Curr Opin Otolaryngol Head Neck Surg. 2011;19(6):434-8.

63. Orestes MI, Chhetri DK, Berke G. Selective reinnervation for bilateral vocal cord paralysis using the superior laryngeal nerve. Laryngoscope. 2015;125(11):2547-50.

64. Mat Baki M, Yu R, Rubin JS, Chevretton E, Sandhu G, Birchall MA. Patient perception of a randomised, controlled trial of laryngeal reinnervation versus thyroplasty for unilateral vocal fold paralysis. J Laryngol Otol. 2015;129(7):693-701.

65. Smith ME, Houtz DR. Outcomes of laryngeal reinnervation for unilateral vocal fold paralysis in children: associations with age and time since injury. Ann Otol Rhinol Laryngol. 2016;125(5): 433-8.

66. Mueller AH, Hagen R, Foerster G, Grossmann W, Baumbusch K, Pototschnig C. Laryngeal pacing via an implantable stimulator for the rehabilitation of subjects suffering from bilateral vocal fold paralysis: a prospective first-in-human study. Laryngoscope. 2016;126(8):1810-6. 
67. Mueller AH. Laryngeal pacing for bilateral vocal fold immobility. Curr Opin Otolaryngol Head Neck Surg. 2011;19(6):439-43.

68. Li L, Li Y, Huang R, Yin J, Shen Y, Shi J. The value of adding transcutaneous neuromuscular electrical stimulation (VitalStim) to traditional therapy for post-stroke dysphagia: a randomized controlled trial. Eur J Phys Rehabil Med. 2015;51(1):71-8.

69. Feinberg AW. Biological soft robotics. Annu Rev Biomed Eng. 2015;17:243-65. A well written paper highlighting the future of biological robotics

70. Mazzolai B, Mattoli V. Robotics: generation soft. Nature. 2016;536(7617):400-1.
71. Dupret-Bories A, Schultz P, Vrana NE, Lavalle P, Vautier D, Debry C. Development of surgical protocol for implantation of tracheal prostheses in sheep. J Rehabil Res Dev. 2011;48(7):851-64.

72. Schultz P, Vautier D, Egles C, Debry C. Experimental study of a porous rat tracheal prosthesis made of T40: long-term survival analysis. Eur Arch Otorhinolaryngol. 2004;261(9):484-8.

73. Debry C, Dupret-Bories A, Vrana NE, Hemar P, Lavalle P, Schultz P. Laryngeal replacement with an artificial larynx after total laryngectomy: the possibility of restoring larynx functionality in the future. Head Neck. 2014;36(11):1669-73. 